\title{
Ice-shelf changes in Pine Island Bay, Antarctica, 1947-2000
}

\author{
ERIC RIGNOT \\ Fet Propulsion Laboratory, California Institute of Technology, 4800 Oak Grove Drive, Pasadena, California 91109-8099, U.S.A. \\ E-mail:eric@adelie.jpl.nasa.gov
}

\begin{abstract}
Aerial photographs from 1947 and 1966, satellite optical imagery from 1973 and 1980, and interferometric synthetic aperture radar (InSAR) data from 1992, 1996 and 2000 are employed to detect ice-shelf changes in Pine Island Bay, Antarctica. The front position of the fast-flowing central ice shelf did not migrate discernibly over the past 50 years. New cracks and rifts appeared in the 1990s, however, that reveal a major weakening of the ice shelf. At the grounding-line center, the ice shelf thinned $21 \mathrm{~m}$ in 8 years. The northern, slow-moving ice shelf also shows signs of decay: (1) its calving front is retreating at an accelerating rate; and (2) the ice shelf is slowly unpinning from its bedrock anchors. These changes are taking place in a region well beyond the temperaturedependent limit of viability of ice shelves, and hence differ from those observed along the Antarctica Peninsula. They are likely due to a change in oceanic forcing, not to a change in air temperature. One possibility is that the documented intrusion of warm circumpolar deep water on the continental shelf has increased basal melting compared to that required to maintain the ice shelf in a state of mass balance, and that this has triggered a general retreat of ice in this sector.
\end{abstract}

\section{INTRODUGTION}

Pine Island Bay is the least studied drainage system of West Antarctica (Vaughan and others, 2001) despite its likely importance to the stability of the West Antarctic ice sheet (Hughes, 1981). Glaciological studies of this region took a new turn in the 1990s with the advent of the European Remote-sensing Satellites ERS-1 and -2. The radar altimeter on board ERS-1 provided information about the surface topography of the drainage basin and ice shelf (Bamber and Bindschadler, 1997). The synthetic aperture radar (SAR) data on board ERS-1 measured the ice-shelf flow velocity more precisely than in prior attempts (Lucchitta and others, 1995) and provided new insights into tributary flow motion (Stenoien and Bentley, 2000). The data also revealed that rapid changes are taking place in this sector: (1) the grounding line of Pine Island Glacier retreated $5 \mathrm{~km}$ between 1992 and 1996 at the glacier center and less on its sides (Rignot, 1998); (2) the drainage basin of Thwaites and Pine Island Glaciers thinned $10 \mathrm{~cm} \mathrm{a}^{-1}$ in the 1990s (Wingham and others, 1998); (3) Pine Island Glacier thinned $1.6 \mathrm{~m} \mathrm{a}^{-1}$ in its lower reaches, with thinning concentrated in areas of fast flow (Shepherd and others, 2001); (4) the basin of Thwaites Glacier is significantly out of balance and its grounding line is retreating (Rignot, 2001); and (5) the flow of Pine Island Glacier accelerated $18 \%$ over the last 8 years over a region $>150 \mathrm{~km}$ in length, including the ice shelf, and the glacier thinned as a result of the acceleration (Rignot and others, 2002).

These glaciological changes call for an explanation. While inland thinning may be related to temporal changes in snow accumulation (Wingham and others, 1998), and ice-shelf thinning may be due to an increase in the intensity of basal melting (Jacobs and others, 1996; Rignot, 1998), coastal thinning of fastmoving grounded ice is clearly an ice dynamic effect (Rignot and others, 2002; Shepherd and others, 2001). The origin of the flow acceleration and its potential future evolution, however, are unknown. More information about the glacier flow boundaries (basal shear stress, geothermal heat flux, lateral friction, tributary flow motion, ice-shelf buttressing) and its temporal evolution is required to address this issue.

Here, we examine available aerial and satellite imagery of Pine Island Bay collected since it was first surveyed in 1947. The multi-sensor imagery is analyzed to detect glaciological changes of the floating ice shelves at the mouth of Pine Island Glacier over the past 50 years and to comment on how these changes may provide insights into the recent glaciological evolution of this sector of the West Antarctic ice sheet.

\section{STUDY AREA}

Pine Island Bay is located at $75^{\circ} \mathrm{S}, 102^{\circ} \mathrm{W}$ in the Amundsen Sea, Antarctica. Figure 1 shows the grounding-line position, ice rises and the zone of tidal flexure (i.e. the $10 \mathrm{~km}$ wide region where ice adjusts to hydrostatic equilibrium) of the ice shelf. For the purpose of the discussion, the floating ice is divided into three sectors: (1) a slow-moving (50-100 $\mathrm{m} \mathrm{a}^{-1}$ ) northern ice shelf, fed by two tributaries flowing at about $150 \mathrm{~m} \mathrm{a}^{-1}$ from the Hudson Mountains and pinned down by numerous ice rises (B-N in Fig. 1); (2) a fast-moving (1000-2700 $\mathrm{m} \mathrm{a}^{-1}$ ) central ice shelf, directly fed by Pine Island Glacier, and with an ice-front position confined between ice rises A and B; and (3) a smaller, southern ice shelf, fed by two tributaries that flow at $300-600 \mathrm{~m} \mathrm{a}^{-1}$, which squeezes its way out through a narrow ice front.

Several volcanoes, knolls and nunataks emerge from the land ice of the Hudson Mountains. These features are easily recognized in multi-sensor imagery. Combined with ice rises along the ice front (Fig. 1), they provide reliable control for the registration of imagery acquired on different years and from different platforms. 


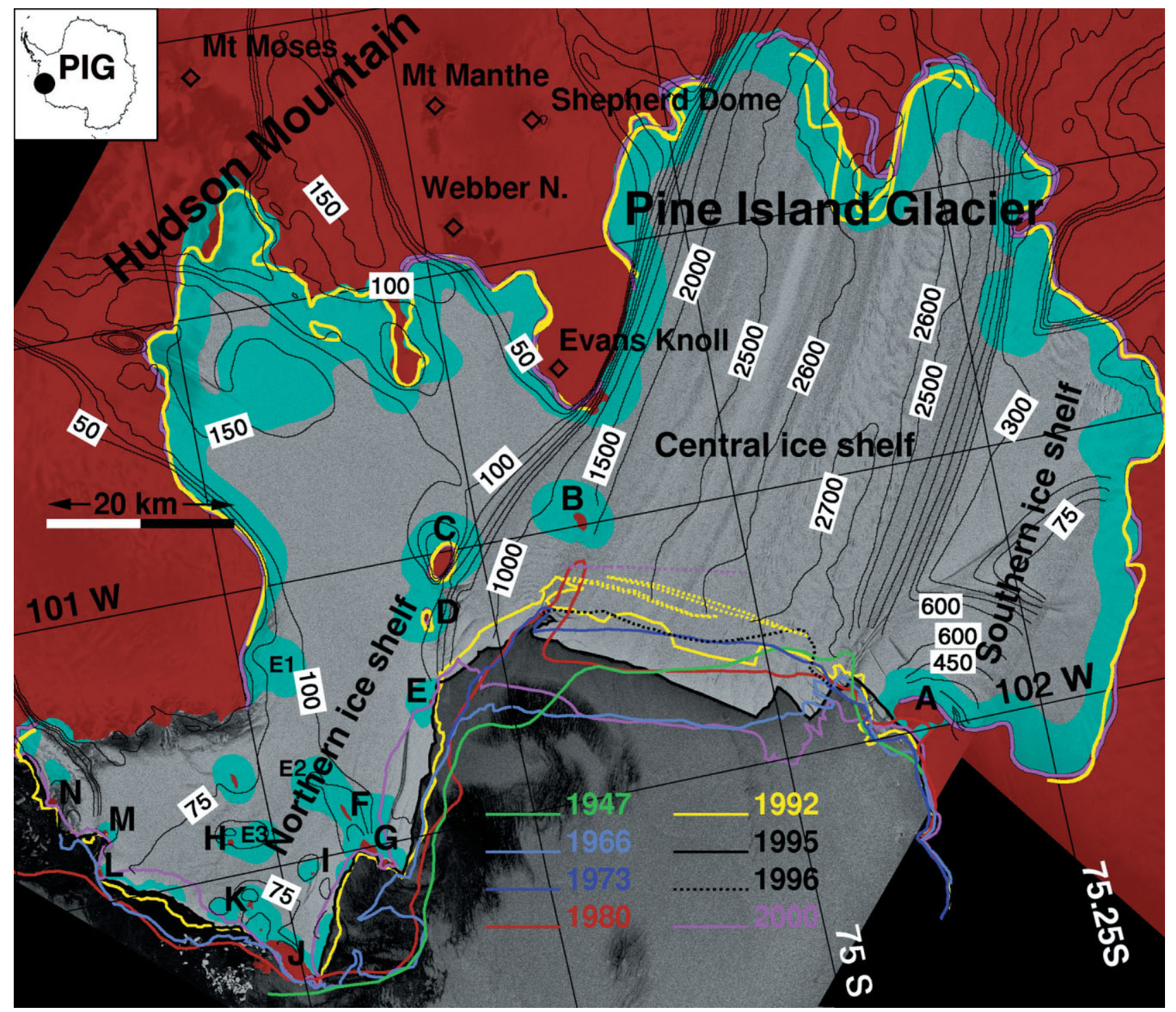

Fig. 1. ERS-1 image of Pine Island Bay ( see inset for location) acquired on 12 November 1995 overlain on the ice-front position in 1947 (green), 1966 (light blue), 1973 (dark blue), 1980 (red), 1992 (yellow), 1995 (black) and 2000 (purple). Dotted lines indicate the location of cracks which appeared prior to a large calving event, with a color coding corresponding to the year of observation (e.g. dotted yellow for 1992 crack). The grounding-line positions in 1992 and 2000 are shown in yellow and purple, respectively. In places where two 1992 or 2000 curves are present, the mapping was done twice with independent pairs. The 1996 grounding-line position (not shown in black) is equivalent to the transition between grounded and floating ice. Tidal flexure zones are colored light blue, with an intensity modulated by radar brightness. Landmarks used for geometric control are indicated with black diamonds and annotated. Ice rises $A-\mathcal{N}$ are discussed in the text. Latitude is plotted every 1/4 degree, longitude every degree. Ice velocity is shown in black contours, in $\mathrm{m} \mathrm{a}^{-1}$. (C) European Space Agency 1996.

\section{METHODS}

Pine Island Bay was discovered in 1947 during the U.S. Navy's Operation High Jump (Byrd, 1947) which included the catapult ship Pine Island. The survey produced the first cartographic map of the region (courtesy of R. Allen, United States Geological Survey (USGS), Reston, VA 2000), but with considerable uncertainty in absolute referencing: comparison of that map with ERS data reveals an absolute offset of $0.5^{\circ}$ in longitude. Yet the presence of recognizable terrain features along the Hudson Mountains permits its registration to a similar map made in 1966 (courtesy of J. Ferrigno, USGS, Reston, VA 1999) from a more accurate and complete set of aerial photos. The 1966 cartography includes vertical photography, which facilitates its registration with satellite image data. Both the 1947 and 1966 maps (scanned into a digital version) were subsequently registered to a reference ERS scene.

The first, cloud-free Landsat Multispectral Scanner
(MSS) image of Pine Island Glacier was acquired in January 1973 (courtesy of B. Lucchitta, USGS, Flagstaff, AZ 1999). In the 1980s, an Advanced Very High Resolution Radiometer (AVHRR) mosaic of Antarctica was assembled by the USGS at a $1 \mathrm{~km}$ spacing (Merson, 1989; and http://terraweb.wr.usgs. gov/TRS/projects/Antarctica/AVHRR.html), which includes data over Pine Island Bay acquired in January 1980.

The ERS satellites (ERS-1 and -2) collected the first time series of radar images of Pine Island Bay, over a decade of austral summers, in early 1992. The imagery has a geolocation accuracy of $50 \mathrm{~m}$ and makes it possible to examine ice flow interferometrically. The ERS-1 image acquired on 12 November 1995 (orbit 22625, track 92) was used here as an absolute reference for all image data. This ERS scene was geocoded using a topographic map generated from interferometric SAR (InSAR) and controlled with the digital elevation model of Antarctica (Bamber and Bindschadler, 1997). Control points $(>20)$ were selected manually in the 


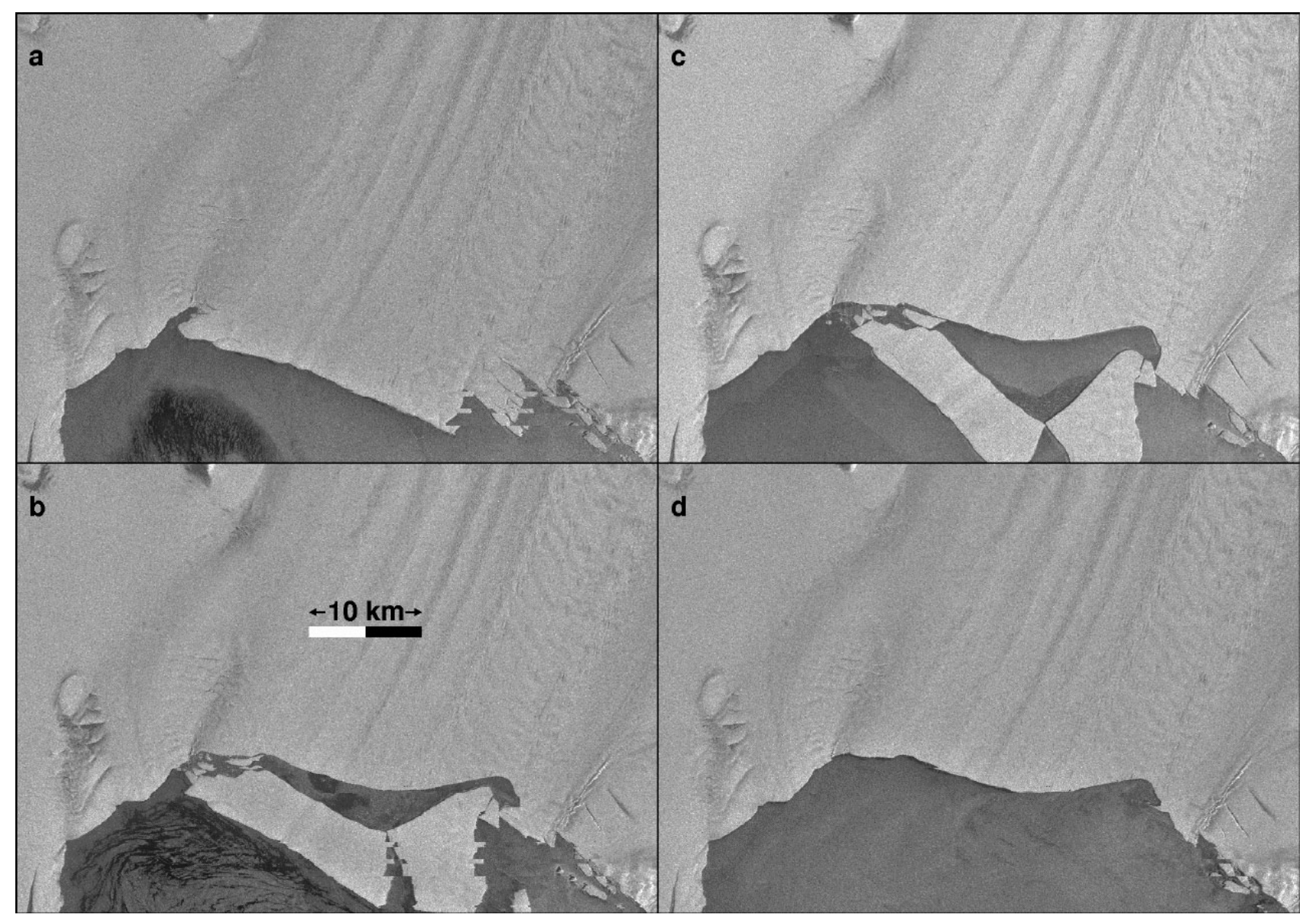

Fig. 2. Calving event in Pine Island Bay from late 1995. (a) ERS-1 image acquired on 12 November 1995; (b) ERS-1 image acquired on 21 January 1996; (c) ERS-2 image acquired on 22 January 1996; and (d) ERS-1 image acquired on 25 February 1996. See Figure 1 for location. (C) European Space Agency 1996.

multi-sensor imagery to perform the registration, excluding features that were not preserved across the imaging spectrum or that changed in position through time. ERS data from different years were registered from amplitude correlation alone, effectively including thousands of control points, after exclusion of areas of fast-moving ice, sea ice and ice-shelf fronts. The resampling of all image data was effected using a polynomial interpolation. The resulting registration accuracy of the imagery in reference to the ERS scene is $1-2 \mathrm{~km}$ for the 1947 map, $500 \mathrm{~m}$ for the $1966 \mathrm{map}, 100 \mathrm{~m}$ for Landsat MSS, $1 \mathrm{~km}$ for AVHRR and better than $50 \mathrm{~m}$ for ERS.

Ice-shelf changes were also studied interferometrically using ERS data from 1992, 1996 and 2000. The migration of the ice-shelf grounding line was mapped in 1992, 1996 and 2000 using the last ERS-1/-2 tandem acquisitions and additional tracks to complete prior mappings (Rignot, 1998). A velocity map of the lower reaches of Pine Island Glacier, including its ice shelves, was assembled using a combination of ERS-1/-2 tracks acquired in November 1995. Details on the generation of this vector velocity map and the subsequent analysis of the retrieved strain field will be given in a follow-on article.

\section{RESULTS}

\subsection{Ice-front changes}

Figure 1 shows changes in ice-shelf front position from 1947 to 2000. The ice front of the central ice shelf fluctuated greatly over the years (e.g. Jenkins and others, 1997), yet there is no discernible change in the mean position of the ice front over the last 50 years. Year-to-year fluctuations in ice-front position in the 1990 s were clearly influenced by periodic, major calving events which removed tabular icebergs up to several $\mathrm{km}$ long and $10-20 \mathrm{~km}$ wide. An example calving event from late 1995 is shown in Figure 2. The ice front retreated $4 \mathrm{~km}$ as a result of this calving event. The two tabular icebergs that calved off the ice shelf rapidly moved away from the glacier front: the images in Figure 2c and d were collected, respectively, 1 day and 35 days after the image in Figure $2 b$.

All ERS data collected in 1992-2000 show a bay free of large tabular icebergs. This situation contrasts with the imagery of the glacier front in 1947 which shows a long series of tabular bergs forming a near-continuum with the ice front, glued together with an ice melange of what is probably broken ice, sea ice, blown snow and smaller bergs (Fig. 3). From the speed of the glacier and the horizontal scale of these bergs, they correspond to calving events cumulated over more than a decade. Similarly, data from 1966, 1973 and 1980 reveal the presence of series of tabular bergs glued to the ice front (Fig. 4). Calf-ice production did not increase after 1980, or the ice front would have experienced a discernible retreat, and there is no seasonal bias in the data, which were all acquired in January-February. The data therefore suggest a reduction in the residence time of tabular bergs at the front of the glacier between the period 1947-80 and the 1990s, which could be due to a change in atmospheric forcing (e.g. wind, surface currents) or a decrease in sea-ice cover.

The ice front of the southern ice shelf did not migrate between 1947 and 2000. In contrast, the front of the northern ice shelf retreated rapidly, especially in recent years. 


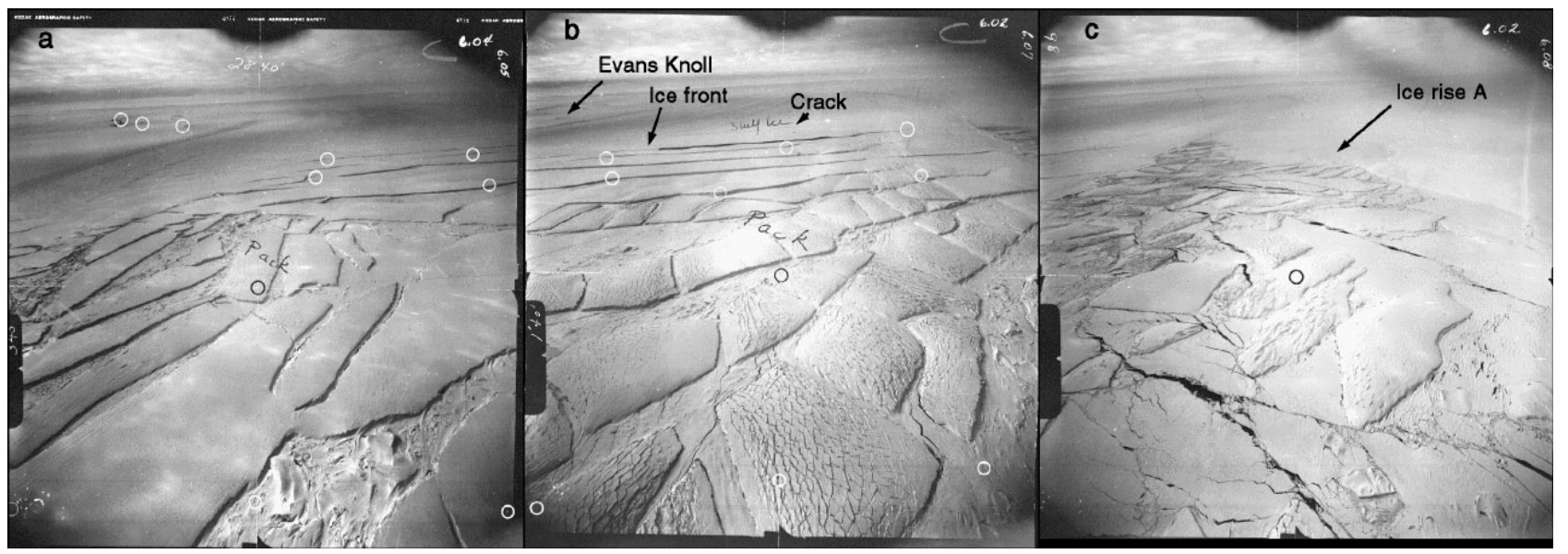

Fig. 3. Aerial photograph of Pine Island Bay recorded in fanuary 1947, with location of Evans Knoll, ice rise A, and ice front going from north $(a, b)$ to south $(c)$. A tenuous crack is visible several $k m$ inland of the inferred ice front. The location of the pictures is shown in Figure 4 a in red. The images are from USGS, Reston, Virginia, TMA5137 series.

The retreat is observed along the sector bordered by ice rises G and J beginning between 1973 and 1980 (Fig. 1), followed by a retreat along $\mathrm{E}-\mathrm{G}$ and $\mathrm{J}-\mathrm{M}$ in subsequent years. A rift between G, I and J increased in width between 1996 and 2000, indicating that a large piece of that sector will calve in the near future. Although the time series of observations is sparse, it is unlikely to have missed readvance events in between since the ice-shelf front moves rather slowly. The image data therefore suggest an accelerating rate of retreat of the northern ice shelf from enhanced calving.

The ice-shelf area between ice rises $\mathrm{E}$ and $\mathrm{M}$ was $930 \mathrm{~km}^{2}$ in 1966. It was reduced by $13.3 \%$ in 1992 (in reference to 1966), $16.7 \%$ in 1996 and $27.2 \%$ in 2000 . The reduction in ice-shelf area over the last 8 years $(14 \%)$ is therefore equivalent to its reduction in the previous three decades. It is also three times greater in 1996-2000 than in 1992-96. The rate of retreat is therefore accelerating with time rather than remaining constant. At the current rate of retreat, half of the 1966 ice shelf will be removed by 2010 .

\subsection{Ice-shelf rifting}

Figure 5 shows new cracks and rifts formed on the central ice shelf prior to 2000 that are much less visible in the 1992 or 1996 imagery, using the same sensor and imaging geometry. These features are likely to be rifts rather than surface crevasses, meaning that they penetrate the entire ice-shelf thickness. Their appearance in ERS imagery is similar to the rifts and cracks observed in the wake of Hemmen Ice Rise, Ronne Ice Shelf, Antarctica (Hartl and others 1994; Rignot and MacAyeal, 1998), and is confirmed by the examination of higher-resolution imagery (Bindschadler and Rignot, 2001).

The floating ice between Evans Knoll and ice rises B and C (Fig. 1) is deeply incised and fractured in 2000 (Fig. 5c and d). As a result, this part of the ice shelf is likely contributing less side-shear resistance to inland flow than in prior years. The sector between B and the ice front is even more heavily rifted, and is probably not contributing any resistance to ice flow in 2000, as discussed below. The entire sector between Evans Knoll and the ice front, or $30 \%$ in length of the northern flank of the central ice shelf, is in a similar state of mechanical decay.

In January 2001, a crack was identified upstream of the 2000 ice front using Landsat 7 imagery (Bindschadler and
Rignot, 2001). The crack location, shown as the dotted purple line in Figure 1, had already been noted in RADARSAT data acquired in September 2000, but went unreported (personal communication from I. Joughin, 2000). ERS imagery subsequently revealed that the crack appeared in $<35$ days between 10 April 2000 (Fig. 5c) and 15 May 2000 (Fig. 5d), suggesting a dynamic rupture of the ice shelf rather than the slow propagation of a rupture tip via viscoelastic processes. The crack was $19 \mathrm{~km}$ long and $200 \mathrm{~m}$ wide near ice rise $\mathrm{B}$ and $<40 \mathrm{~m}$ at its western end in May 2000. The rupture tip of the crack is difficult to locate precisely in the radar imagery due to the presence of image speckle, but the origin of the rupture clearly belongs to a pre-existing rift in the wake of ice rise B (e.g. Fig. 5c). Subsequent imagery (not shown in Fig. 5) indicates that the rift increased in width with time and continued its transverse-flow progression across the shelf. The detached portion of the ice shelf (between B and the ice front) is therefore moving faster than the rest of the ice shelf, and as such is no longer participating in the overall ice-shelf resistance to inland ice flow.

ERS imagery shows that a crack of similar width and length occurred $2 \mathrm{~km}$ downstream in 1992 and $4.5 \mathrm{~km}$ downstream in 1996 (Fig. 1). Hence, ice-shelf rupturing took place near that location in the past, yet there is no prior record of a crack opening this far upstream and accompanied by fresh lines of enhanced rifting near the ice-shelf pinning points.

\subsection{Grounding-line migration}

Figure 6 shows the migration of the grounding line of Pine Island Glacier between 1992, 1996 and 2000, effectively updating the results in Rignot (1998). Figure 1 shows the grounding-line migration between 1992 and 2000 for the northern and southern ice shelves. The grounding-line mapping was performed using double-difference interferograms corrected for topography. Surface topography was derived from a combination of InSAR data and radar altimetry data. The results show that the grounding-line retreat is most pronounced along Pine Island Glacier, which continued its retreat after 1996. In contrast, little retreat is observed along the southern and northern ice shelves (Fig. 1).

The 2000 grounding-line position of Pine Island Glacier is more sinuous than those obtained from prior years, which requires an explanation. One factor is the presence of a lowslope region immediately upstream of the 1996 grounding 


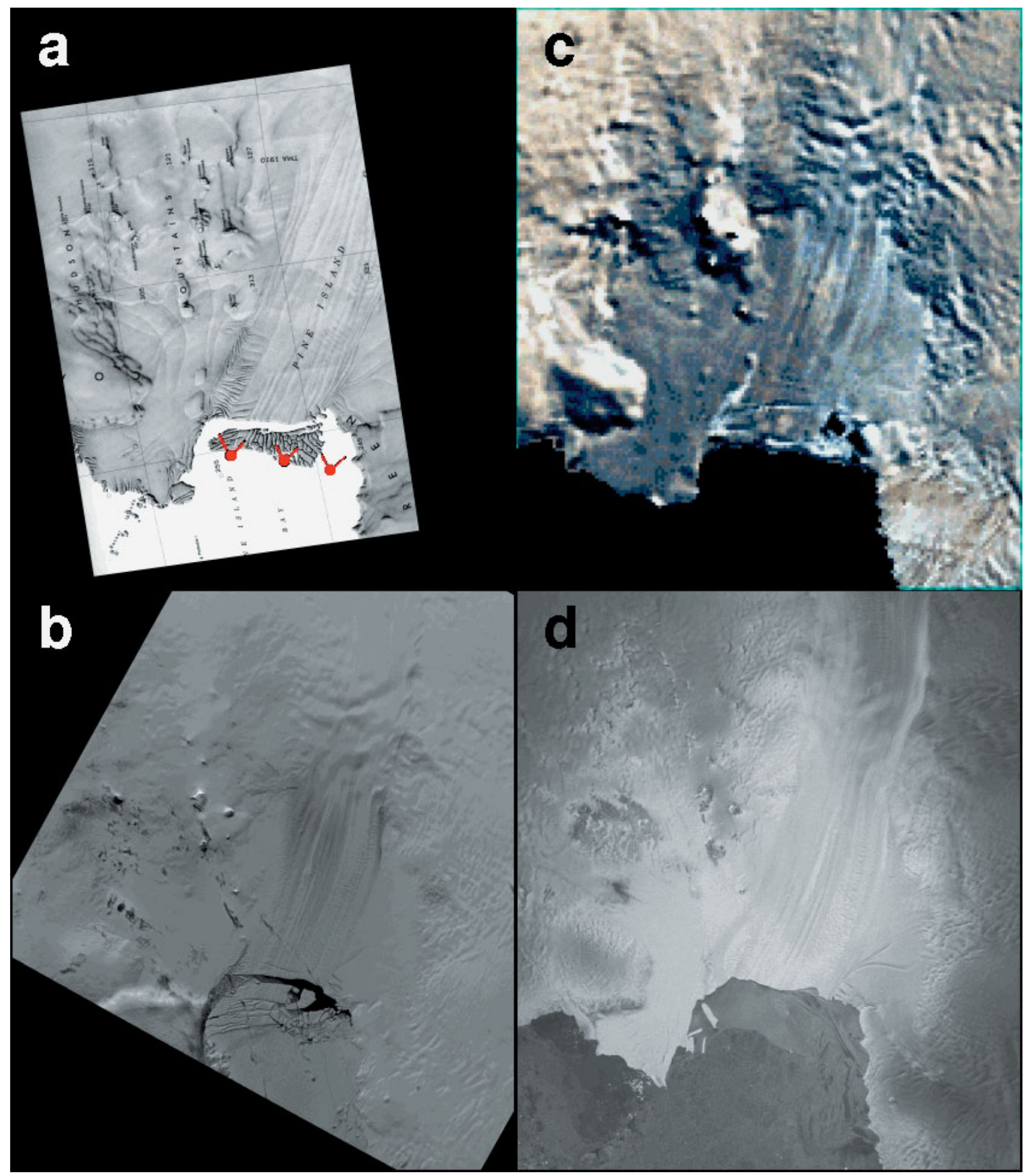

Fig. 4. Pine Island Bay in (a) January 1966 (vertical aerial photography), (b) January 1973 (Landsat MSS), (c) January 1980 ( AVHRR) and (d) September 1997 (RADARSAT) from multiple sensors. The locations of the photographs in Figure 3 are shown by red angles in (a). (C) Canadian Space Agency 1997.

line, identified as an ice plain by Corr and others (2001). The grounding line is likely migrating more significantly back and forth with changes in ocean tide as the ice retreats in a sector which is already close to hydrostatic equilibrium. A second factor is a stronger contamination of the interferometric signal with flow changes in 2000 than in 1992 and 1996. The glacier velocity is $2500 \mathrm{~m} \mathrm{a}^{-1}$, and the flow acceleration is $2 \% \mathrm{a}^{-1}$ (Rignot and others, 2002). In 1992, the grounding line was mapped by differencing two 6 day interferograms acquired 6 days apart, i.e. over a time period for which the glacier flow was not expected to change at a detectable level, i.e. about $0.8 \mathrm{~m} \mathrm{a}^{-1}$. In 1996, the two 1 day interferograms which we differenced were acquired 35 days apart. In 2000, the mapping combined pairs acquired 105 days apart (no other data were acquired in between those dates), implying a change in velocity of $14 \mathrm{ma}^{-1}$, equivalent to half an interferometric fringe at the glacier center and less on the sides. The flow acceleration may therefore have slightly contaminated the differential fringes.

Rignot (1998) used the largest retreat rate at the glacier center to estimate glacier thinning. To obtain an estimate that may be more readily comparable with satellite radar altimetry data (which average results over several $\mathrm{km}$ ), the rate of retreat was here re-evaluated along a $14 \mathrm{~km}$ long segment labeled A in Figure 6, at the glacier center. The calculated mean retreat is $4.4 \mathrm{~km}$ for $1992-2000$ and $2.5 \mathrm{~km}$ for 1992-96. Using a glacier slope of $-0.5 \%$ and a bed slope of $+1 \%$ (both slopes are counted positive upwards, as in Rignot (1998)), the inferred rate of glacier thinning is $1.9 \mathrm{~m} \mathrm{a}^{-1}$ for $1992-2000$ and $2.1 \mathrm{~m} \mathrm{a}^{-1}$ for $1992-96$. These 


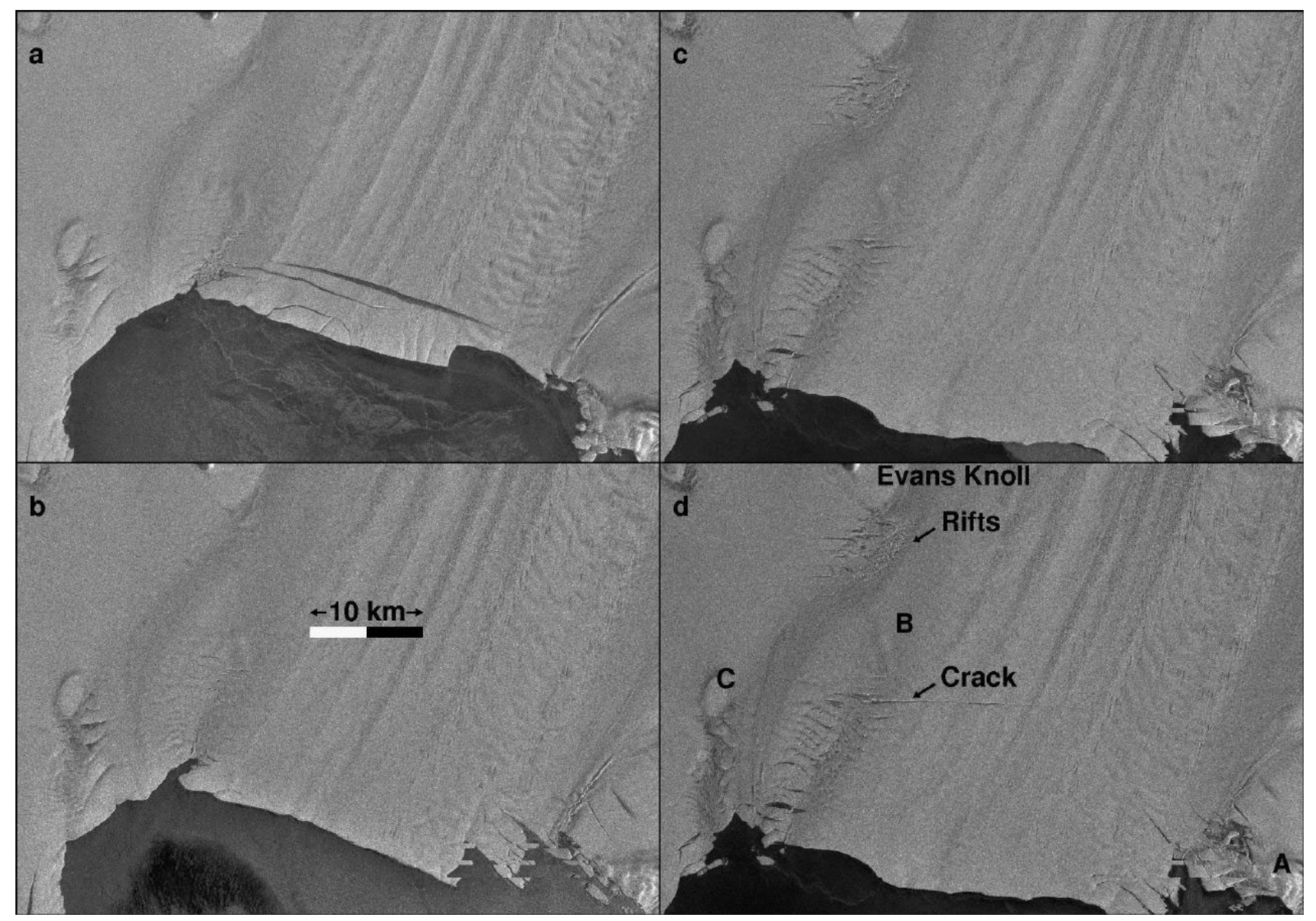

Fig. 5. ERS-1 image of ice-shelf rifting in Pine Island Bay on (a) 15 February 1992, (b) 12 November 1995, (c) 10 April 2000 and (d) 15 May 2000. Ice rises A-C (see Fig. 1) are indicated, along with Evans Knoll. C)European Space Agency 2000.

results are consistent with Shepherd and others' (2001) estimate of $1.6 \mathrm{~m} \mathrm{a}^{-1}$ thinning near the grounding-line center. No particular trend in ice thinning is noted over the 8 year time period.

A retreat of the grounding line is detected along several of the tributaries of Pine Island Glacier, but the amplitude of the retreat is much less than along Pine Island Glacier, and closer to the range of variability expected from changes in oceanic tides. A retreat is detected for the tributary at $74.5^{\circ} \mathrm{S}, 100^{\circ} \mathrm{W}$, west of Mount Moses (Fig. 1); no groundingline migration data are available along the second tributary that flows between Mount Moses and Mount Manthe; a retreat is detected on the tributary flowing south of Shepherd Dome, on the northern flank of Pine Island Glacier at $75^{\circ} \mathrm{S}$, $99.5^{\circ} \mathrm{W}$ (Fig. 1). In contrast, the level of retreat on the tributaries feeding into the southern ice shelf is negligible.

\subsection{Ephemeral grounding}

Figure 7 shows the evolution of areas of ephemeral grounding on the northern ice shelf between 1992 and 2000. Ephemeral grounding means that the ice shelf is only grounded at low tide but not at high tide (Schmeltz and others, 2001). In contrast, an ice rise is grounded at all tides. The magnitude of tidal flexing recorded with InSAR between the center of a zone of ephemeral grounding and the surrounding freely floating ice is always less than that recorded between an ice rise and floating ice. Hence, fewer interferometric fringes are counted across the tidal flexure zone of an area of ephemeral grounding than across the flexure zone of an ice rise.

If the thickness of the ice shelf decreases with time around an area of ephemeral grounding, the duration of contact between the ice-shelf bottom and bedrock will decrease during the tidal cycle, hence the number of displacement fringes recorded across the flexure zone will be less. The exact reduction in the number of fringes observed across the area of ephemeral grounding, however, will also depend on the oceanic tides at the time of imaging. For instance, if all imagery were acquired at low tide, it would not be possible to distinguish an ice rise from areas of ephemeral grounding. Conversely, imagery acquired at high tide would only detect ice rises.

Here, the data show that the ice shelf was nearly grounded at E1-E3 (Fig. 1) in 1992, and nearly ungrounded in 2000 (Table 1). Conversely, no new zones of partial grounding appeared in 2000 that were not present in prior years. This trend is indicative of thinning and unpinning of the ice shelf.

The tidal displacements calculated using the FES99 tidal model (F. Lefevre and others, unpublished information) are compared with the differential tides measured with InSAR in Table 1. InSAR measures changes in tidal displacement between three (in the case of 1992 data) or four epochs (in the case of 1996 and 2000 data). Table 1 indicates that the FES99 tidal predictions are accurate to first order (standard deviation is $\pm 9 \mathrm{~cm}$ ). This accuracy is low compared to the nominal performance of the FES99 tidal model at lower latitudes $(2-3 \mathrm{~cm})$, but this is expected since the coastal regions of Antarctica are not constrained by satellite altimetry data and the bathymetry of Pine Island Bay is poorly known.

The precision of the FES99 tidal model is sufficient to allow the following observations to be made. First, the disappearance of zones of ephemeral grounding is not an artefact of oceanic tides. This would be the case if, for instance, 


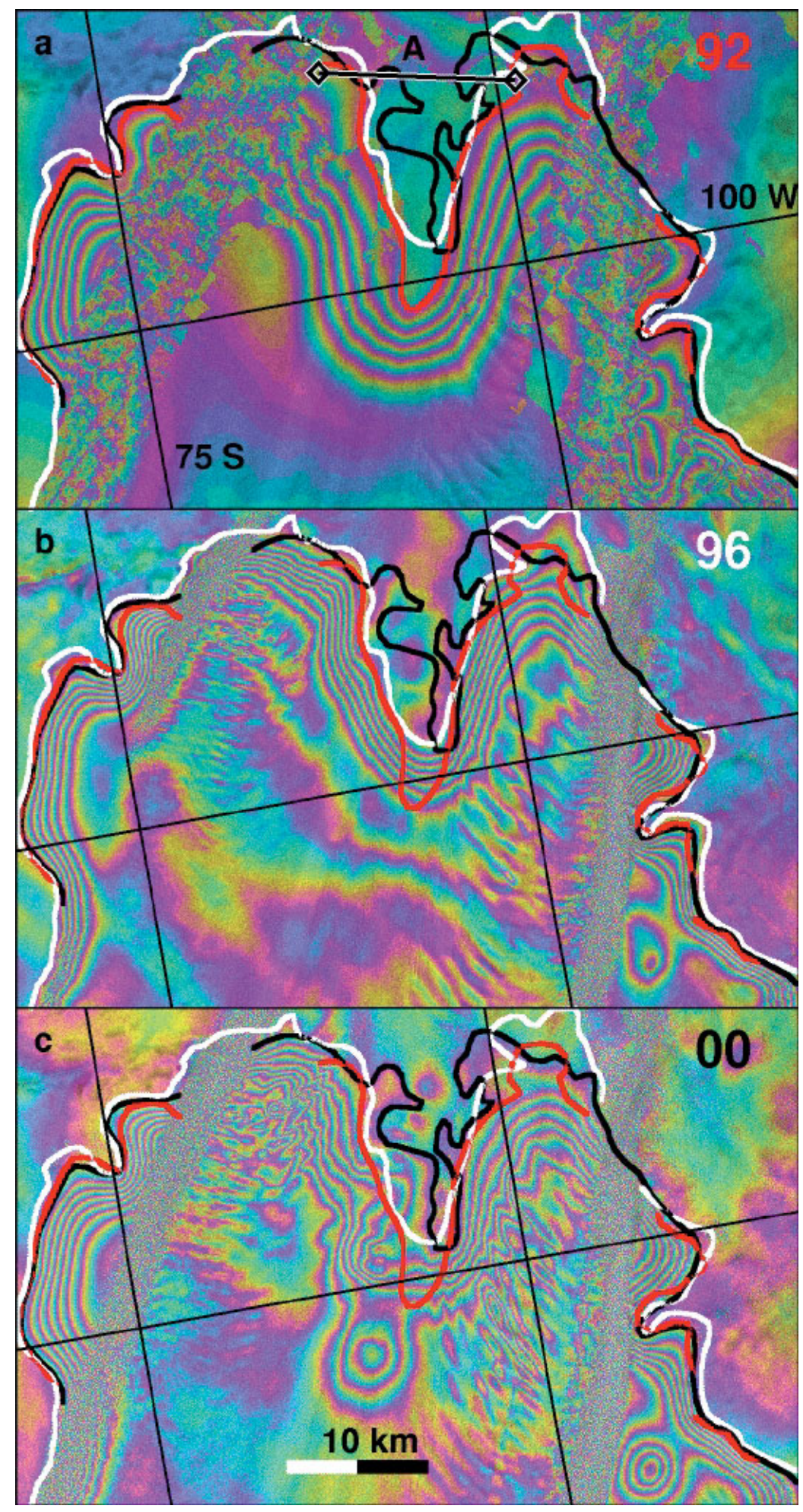

Fig. 6. Grounding-line retreat of Pine Island Glacier between (a) 1992 (red) (pair 3418, 3375 and 3461 in Table 1) (b) 1996 (white) (pair 23627, 24128 in Table 1), and (c) 2000 (black) (pair 43599, 45102 in Table 1) overlain on an image of tidal deformation for each epoch. One color cycle (from purple to yellow, blue and purple again) represents a $3 \mathrm{~cm}$ increment in vertical motion of the floating ice. Segment A, discussed in the text, is used to calculate an average rate of retreat at the glacier center.

the lowest tide in 2000 - lowest tide means greater potential of contact with bedrock - were significantly more positive (i.e. upwards) than in 1996 or 1992. Table 1 shows that the lowest tide in the 2000 data $(-45.1 \mathrm{~cm})$ is comparable to that in the $1996(-33.1 \mathrm{~cm})$ and $1992(-36 \mathrm{~cm})$ data. Second, if we assume that the tidal predictions are correct, it is possible to estimate the mean-sea-level water-column thickness underneath areas of ephemeral grounding and determine how it changed with time. For instance, in 1992 (Fig. 7a), E2 displayed 6 tidal fringes (or $18 \mathrm{~cm}$ ), whereas the full tidal displacement was 11 fringes (or $33 \mathrm{~cm}$ ). E2 must have been in contact with bedrock at the lowest tide $(-36 \mathrm{~cm})$, otherwise there would be no ephemeral grounding, but it could not have been in contact with bedrock at the highest tide $(-4 \mathrm{~cm})$, otherwise it would look like an ice rise. The $18 \mathrm{~cm}$ displacement exhibited by E2 therefore implies a mean-sealevel water-column thickness of $33-18=15 \mathrm{~cm}$. In 2000, E2 exhibited 0.5 fringes or $1 \mathrm{~cm}$. It must have been in contact with bedrock only at the lowest tide $(-45 \mathrm{~cm})$, which indicates a water-column thickness of $45-1=44 \mathrm{~cm}$. This implies a reduction in ice-shelf thickness of $(44-15)=29 \mathrm{~cm}$ in 8 years at $\mathrm{E} 2$. The same exercise repeated at $\mathrm{E} 3$ yields an increase in 


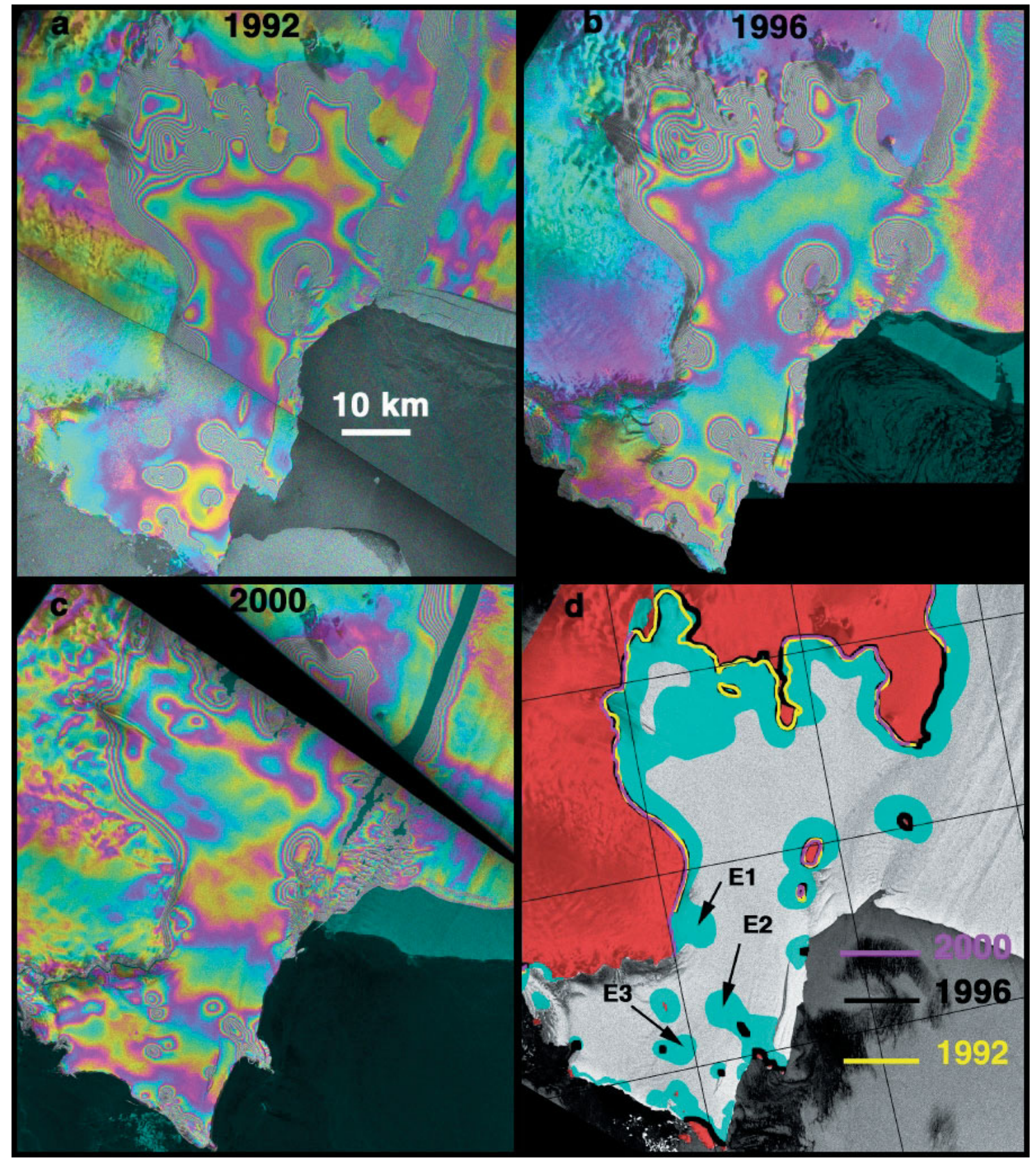

Fig. 7. Tidal deformation of the northern ice shelf ( see Fig. 1 for location) in (a) 1992, (b) 1996 and (c) 2000. One color cycle (from purple to yellow, blue and purple again) represents a $3 \mathrm{~cm}$ increment in vertical displacement of the ice shelf due to a change in oceanic tide. Areas of ephemeral grounding in E1-E3 in (d) progressively disappear from $(a-c)$ due to ice-shelf thinning.

water-column thickness of $33 \mathrm{~cm}$ in 8 years. At E1, the watercolumn thickness increased from $6 \mathrm{~cm}$ in 1992 to $42 \mathrm{~cm}$ in 2000. Overall, the increase in mean-sea-level water thickness is $4.1 \pm 0.5 \mathrm{~cm} \mathrm{a}^{-1}$ over $\mathrm{E} 1-\mathrm{E} 3$, which is equivalent to a reduction in ice thickness of about $4.5 \mathrm{~cm} \mathrm{a}^{-1}$.

This calculated thinning rate is low, but it is measured over a part of the ice shelf where basal melting is likely to be low: the water-column thickness is shallow, hence limiting heat-flow exchanges, and the ice-shelf thickness is only 100 $200 \mathrm{~m}$ vs $1200 \mathrm{~m}$ for Pine Island Glacier. Basal melting should be at least one order of magnitude less in that region than in the deeper part of the sub-ice cavity of Pine Island Glacier since the melting point of ice decreases linearly with increasing water pressure and hence the depth of the ice draft. The more important aspect of the observed thinning, however, is that the ice shelf is slowly unpinning from its anchor points.

\section{DISCUSSION}

Sediment analysis by Kellogg and Kellogg (1987) suggested the presence of a more extensive ice shelf in Pine Island Bay in the past, yet with considerable uncertainty in the timing of the retreat. The remote-sensing data presented here indicate that the ice shelf was not significantly larger in 1947 than at present, so that any retreat of a more extensive paleo ice shelf must have started > 50 years ago. Ice-shelf changes seemed rather subdued between 1947 and 1973, but apparently began to accelerate in the 1980s. The central ice shelf, which is directly fed by Pine Island Glacier, now thins at $1.9 \mathrm{~m} \mathrm{a}^{-1}$ and shows signs of rifting and rupturing along its northern flank that were not visible in earlier imagery. The rapid grounding-line thinning of the central ice shelf is for the most part explained by the flow acceleration of Pine Island Glacier, as 
Table 1. ERS-1 orbit number, tidal displacement measured with InSAR, and tidal displacements predicted by FES99 at the time of acquisition of ERS data in Pine Island Bay

\begin{tabular}{|c|c|c|c|c|c|c|c|}
\hline E11 (orb/day/hr) & E12 (orb/day/hr) & $\operatorname{InSAR}$ & FES99 & E11 & E21 & E1 2 & $E 22$ \\
\hline $22614(13828 / 13.8)$ & $24117(13933 / 13.8)$ & -8.7 & -17.6 & +27.4 & +32.6 & -10.2 & -22.6 \\
\hline $23616(13898 / 13.8)$ & $24117(13933 / 13.8)$ & -16.5 & -20.3 & -41.6 & -33.8 & -10.2 & -22.6 \\
\hline $22625(13829 / 8.4)$ & $24128(13934 / 8.4)$ & +15.6 & +17.7 & +35.2 & +29.8 & -33.1 & -20.8 \\
\hline $23627(13899 / 8.4)$ & $24128(13934 / 8.4)$ & $+33.6^{*}$ & +21.2 & +81.2 & +72.2 & -33.1 & -20.8 \\
\hline $43599(15294 / 14.3)$ & $45102(15399 / 14.3)$ & $-12.0^{*}$ & +4.0 & +37.4 & +34.2 & -45.1 & -44.3 \\
\hline $43656(15298 / 13.8)$ & $45159(15403 / 13.8)$ & +15.7 & +23.9 & +5.4 & -11.1 & -26.7 & -19.4 \\
\hline E11 (orb/day/hr) & E12(orb/day/hr) & E13(orb/day/hr) & InSAR & FES99 & E11 & E12 & E13 \\
\hline $3375(12485 / 14.4)$ & 3418(12488/14.4) & 3461 (12491/14.4) & $-33.0^{*}$ & -30.6 & -4.8 & -35.7 & -36.0 \\
\hline $3260(12477 / 13.8)$ & $3346(12483 / 13.8)$ & $3432(12489 / 13.8)$ & +40.4 & +46.2 & -44.5 & -3.9 & -50.1 \\
\hline $2970(12457 / 8.3)$ & $3056(12463 / 8.3)$ & $3142(12469 / 8.3)$ & +63.3 & +56.1 & -4.6 & 23.9 & -3.7 \\
\hline
\end{tabular}

Notes: The notation is as follows: E1 1 orb, orbit number of ERS-1 reference scene for first pair; day, Julian day since 1 January 1958; hr, hour GMT; E1 2, ERS-1 reference scene for second pair; InSAR, measured tidal difference between the two ERS pairs; FES99, predicted tidal difference between the two pairs; E $i$, predicted tide for ERS- $i$ pair $i(i=1,2)$. In 1996-2000 (rows 1-6), InSAR measures (tide $E 11-$ tide $_{E 21}-$ tide $_{E 12}+$ tide $_{E 22}$ ); and FES99 is calculated from the predictions listed in column 5-8 as (column 5-column 6) - (column 7 - column 8). E1 1 and E2 1 are separated by 1 day, E1 2 and E2 2 are separated by 1 day, and E1 1 and E1 2 are separated by a multiple of 35 days. In 1992 (bottom three rows), InSAR measures (tide $E 11-$ tide $_{E 11}+$ tide $E 11-$ tide $_{E 13}$ ), where E1 1, E1 2 and E1 3 are separated by 6 days (only every other orbit was acquired, and ERS-1 was in a 3 day repeat cycle). Asterisks in column 3 denote the tidal pairs employed in Figure 7.

discussed by Rignot and others (2002). The thinning of the northern ice shelf is less likely to be the result of flow changes, because the creep rates are much lower; it probably implies an increase in basal melting above that which would maintain the ice shelf in a state of mass balance.

The ongoing ice-shelf retreat in Pine Island Bay is unlike the more spectacular and well-documented collapses recorded further north along the Antarctic Peninsula (Doake and others, 1998). The collapse of the Larsen and Wordie Ice Shelves has been attributed to a vigorous regional increase in air temperature which brought those ice shelves under the limit of viability as determined by Mercer (1978). Water-filled crevasses (Doake and others, 1998) and warmer summer temperatures (Scambos and others, 2000) caused enhanced crevassing, rifting and breaking-up of those ice shelves. In Pine Island Bay, air temperatures are much lower than along the Antarctic Peninsula, and surface melting, if any, is unlikely to produce water-filled crevasses, at least not ones that have been documented with remote-sensing data. Processes other than air temperature and surface melt must control the mechanical competence and evolution of ice in Pine Island Bay.

One major factor in the evolution of the ice shelves should be basal melting. Basal melting is particularly effective in Pine Island Bay due to the presence of warm circumpolar deep water (CDW), which has long been known to intrude onto the continental shelf (Jacobs and others, 1996), and which is typically $2{ }^{\circ} \mathrm{C}$ warmer than at most other locations on the Antarctic shelf. Basal melting is very sensitive to ocean temperature (Hellmer and others, 1998), and hence to the presence of CDW. An increase in basal melting compared to that required to maintain the ice shelves in a state of mass balance would obviously cause the ice shelves to thin. As the grounding line of the glaciers starts to retreat, basal melting would further increase because the ice sheet would retreat into a deeper basin.

As an equivalent to the water-filled surface crevasses pervading on the Larsen and Wordie Ice Shelves, bottom crevasses generated in the wake of grounding lines, ice rises and floating shear margins (Jezek and Bentley, 1983) may propagate upwards more easily through the ice column if eroded and/or warmed by a tidally mixed influx of warm water. Bottom crevasses are most likely to be at the origin of the rifts observed in 2000 since water-free surface crevasses should not be able to evolve into rifts (Weertman, 1980; Van der Veen, 1998).

What is the evidence for ongoing changes in the Bellingshausen and Amundsen Seas sector of West Antarctica? One evidence is a 20\% decline in sea-ice cover between 1973 and 1993 reported by Jacobs and Comiso (1997). They attributed this trend to enhanced surface currents caused by a change in atmospheric forcing, or to the upwelling of warm CDW on the continental shelf. More recent analysis indicates that the trend persisted at least through 1998 (Kwok and Comiso, 2002; personal communication from J. C. Comiso, 2001). It is the most significant negative trend in sea-ice cover in Antarctica. Kwok and Comiso (2002) further noted that the entire Bellingshausen/Amundsen Sea sector has a significant correlation with the Southern Oscillation (SO), which is unique in Antarctica. Yet there is no significant trend in the $\mathrm{SO}$ over the last 20 years which would explain the observed negative trend in sea-ice cover.

A reduction in sea-ice cover alters the vertical heat flux, brine formation and sub-ice-shelf circulation. Nicholls (1997) argues that this results in a reduction rather than an increase in melt intensity since the thermohaline convection responsible for melting is reduced. This conclusion applies, for instance, to the case of the Ronne Ice Shelf for which a thermohaline convection is the principal mechanism of basal erosion. It does not apply to the ice shelves in Pine Island Bay where a second mechanism of basal erosion involving intermediatedepth warm-water inflows from the slope-front region directly onto the ice shelf (Jacobs and others, 1992) is believed to be the main factor responsible for the observed high melt rates (Jacobs and others, 1996).

Another line of evidence for anomalies in this sector of Antarctica is that ice shelves throughout the Amundsen and Bellingshausen Seas are experiencing high rates of thinning at present, as observed with ERS radar altimetry (H.J. Zwally and others, unpublished information). The observed 
thinning rates (up to several $\mathrm{m} \mathrm{a}^{-1}$ in some sectors) are too large to be attributed to changes in snow precipitation, surface melt or creep flow. They must be thinning principally by basal ablation.

\section{GONCLUSIONS}

An analysis of glacier imagery collected in Pine Island Bay over half a century suggests that its floating glacier ice is retreating and weakening, with a marked acceleration of that trend in the last decade. The satellite observations do not suggest that the ice shelves in this region are in steady state at present. The coincidence of the retreat of the central ice shelf with the flow acceleration of Pine Island Glacier is not fortuitous and suggests that ongoing changes in floating ice may have had an impact on the inland flow of ice. Most of the buttressing force exerted by the ice shelf onto the grounded ice is from lateral shear (ice rises A and B exert little buttressing at the grounding line), which in turn is directly influenced by the presence of rifts and crevasses along the shear margins. A rifted shear margin will exert less side shear, and hence decrease lateral resistance to inland flow, and allow faster rates of ice discharge from inland. This issue is addressed in more detail in a forthcoming paper on a model study of Pine Island Glacier.

Although Pine Island Bay lies well south of the limit of viability of ice shelves suggested by Mercer $(1978)\left(-5^{\circ} \mathrm{C}\right.$ mean January temperature), its ice shelves are almost certainly thinning, weakening and fracturing at present and its grounding line is retreating. The cause of thinning and weakening is unlikely to be a change in surface conditions, such as air temperature, but could be a change in oceanic forcing related, for instance, to the intrusion of warm CDW over the continental ice shelf. This possibility suggests that oceanic forcing should be considered as a factor equally important to atmospheric forcing in predictive studies of the evolution of Antarctic ice shelves in a warmer climate.

\section{ACKNOWLEDGEMENTS}

This work was performed at the Jet Propulsion Laboratory, California Institute of Technology, under a contract with the National Aeronautics and Space Administration (NASA) Cryospheric Sciences Program. I thank the reviewers, C. S. M. Doake and C. R. Bentley, and the Scientific Editor, J.W. Glen, for helping me greatly improve the quality of the manuscript, and the European Space Agency's VECTRA project and NASA's Alaska SAR Facility for providing the ERS radar data employed in this study.

\section{REFERENGES}

Bamber, J. L. and R. A. Bindschadler. 1997. An improved elevation dataset for climate and ice-sheet modelling: validation with satellite imagery. Ann. Glaciol., 25, 439-444.

Bindschadler, R. A. and E. Rignot. 2001. Crack! In the polar night. Eos, 82(43), 497, 505.

Byrd, R. E. 1947. Our navy explores Antarctica. Nat. Geogr. Mag., 92(4), 429-522.
Corr, H. F. J., C. S. M. Doake, A. Jenkins and D. G. Vaughan. 2001. Investigations of an "ice-plain" in the mouth of Pine Island Glacier, Antarctica. 7. Glaciol., $47(156), 51-57$.

Doake, C. S. M., H. F. J. Corr, H. Rott, P. Skvarca and N.W. Young. 1998. Breakup and conditions for stability of the northern Larsen Ice Shelf, Antarctica. Nature, 391 (6669), 778-780.

Hartl, P., K.-H. Thiel, X. Wu, C. S. M. Doake and J. Sievers. 1994. Application of SAR interferometry with ERS-1 in the Antarctic. Earth Obs. Q, $43,1-4$.

Hellmer, H. H., S. S. Jacobs and A. Jenkins. 1998. Oceanic erosion of a floating Antarctic glacier in the Amundsen Sea. In Jacobs, S. S. and R. F. Weiss, eds. Ocean, ice and atmosphere: interactions at the Antarctic continental margin. Washington, DC, American Geophysical Union, 83-100. (Antarctic Research Series 75.

Hughes, T.J. 1981. Correspondence. The weak underbelly of the West Antarctic ice sheet. F. Glaciol., 27(97), 518-525.

Jacobs, S. S. and J. C. Comiso. 1997. Climate variability in the Amundsen and Bellingshausen Seas. F. Climate, 10 (4), 697-709.

Jacobs, S. S., H. H. Hellmer, C. S. M. Doake, A. Jenkins and R. M. Frolich. 1992. Melting of ice shelves and the mass balance of Antarctica. F. Glaciol., 38(130), 375-387.

Jacobs, S. S., H. H. Hellmer and A. Jenkins. 1996. Antarctic ice sheet melting in the southeast Pacific. Geophys. Res. Lett., 23(9), 957-960.

Jenkins, A., D. G. Vaughan, S. S. Jacobs, H. H. Hellmer and J. R. Keys. 1997. Glaciological and oceanographic evidence of high melt rates beneath Pine Island Glacier, West Antarctica. f. Glaciol., 43(143), 114-121.

Jezek, K. C. and C. R. Bentley. 1983. Field studies of bottom crevasses in the Ross Ice Shelf, Antarctica. f. Glaciol., 29(101), 118-126.

Kellogg, T. B. and D. E. Kellogg. 1987. Recent glacial history and rapid ice stream retreat in the Amundsen Sea. F. Geophys. Res., 92(B9), 8859-8864.

Kwok, R. and J. C. Comiso. 2002. Southern Ocean climate and sea ice anomalies associated with the Southern Oscillation. F. Climate, 15(5), 487-501.

Lucchitta, B. K., C. E. Rosanova and K. F. Mullins. 1995. Velocities of Pine Island Glacier, West Antarctica, from ERS-1 SAR images. Ann. Glaciol., 21, 277-283.

Mercer, J. H. 1978. West Antarctic ice sheet and $\mathrm{CO}_{2}$ greenhouse effect: a threat of disaster. Nature, 271 (5643), 321-325.

Merson, R. H. 1989. An AVHRR mosaic image of Antarctica. Int. F. Remote Sensing, 10(4-5), 669-674.

Nicholls, K.W. 1997. Predicted reduction in basal melt rates of an Antarctic ice shelf in a warmer climate. Nature, 388(6641), 460-462.

Rignot, E. J. 1998. Fast recession of a West Antarctic glacier. Science, 281 (5376), 549-551.

Rignot, E. 2001. Evidence for rapid retreat and mass loss of Thwaites Glacier, West Antarctica. 7. Glaciol., 47(157), 213-222.

Rignot, E. and D. R. MacAyeal. 1998. Ice-shelf dynamics near the front of the Filchner-Ronne Ice Shelf, Antarctica, revealed by SAR interferometry. F. Glaciol., 44(147), 405-418.

Rignot, E., D. G. Vaughan, M. Schmeltz, T. Dupont and D. MacAyeal. 2002. Acceleration of Pine Island and Thwaites Glaciers, West Antarctica. Ann. Glaciol., 34, 189-194.

Scambos, T. A., C. Hulbe, M. Fahnestock and J. Bohlander. 2000. The link between climate warming and break-up of ice shelves in the Antarctic Peninsula. 7. Glaciol., 46(154), 516-530.

Schmeltz, M., E. Rignot and D. R. MacAyeal. 2001. Ephemeral grounding as a signal of ice-shelf change. 7. Glaciol., 47(156), 71-77.

Shepherd, A., D. J. Wingham, J. A. D. Mansley and H. F. J. Corr. 2001. Inland thinning of Pine Island Glacier, West Antarctica. Science, 291(5505), 862-864.

Stenoien, M. D. and G. R. Bentley. 2000. Pine Island Glacier, Antarctica: a study of the catchment using interferometric synthetic aperture radar measurements and radar altimetry. F. Geophys. Res., 105(B9), 21,761-21,779.

Van derVeen, C. J. 1998. Fracture mechanics approach to penetration of bottom crevasses on glaciers. Cold Reg. Sci. Technol., 27(3), 213-223.

Vaughan, D. G. and 9 others. 2001. A review of Pine Island Glacier basin, West Antarctica: hypotheses of instability vs. observations of change. In Alley, R. B. and R. A. Bindschadler, eds. The West Antarctic ice sheet: behavior and environment. Washington, DC, American Geophysical Union, 237-256. (Antarctic Research Series 77.)

Weertman, J. 1980. Bottom crevasses. F. Glaciol., 25(91), 185-188.

Wingham, D. J., A. L. Ridout, R. Scharroo, R. J. Arthern and C. K. Shum. 1998. Antarctic elevation change 1992 to 1996. Science, 282(5388), 456-458. 